menced and run its progress, even in the space of three weeks; for, he obserred, that the rapidity with which fungus hamatodes pursued its course, is a prominent diagnostic feature, and in confirmation of this, he related a case occurring at the head of the tibia in a patient 2\% ycars of age. The affection came on about Christmas, and had so far extended, that early in the month of April it was necessary to amputate the limb; six days after the operation, ulceration of the artery ensued, and the case proved fatal from hamorrhage. Upon examining the limb, it was found that two-thirds of the head of the bone were destroyed, the surrounding muscular texture was implicated, and a tuber. cle was found in the liver.

With respect to the displacement of the heart, as observable in Mr. 'Travers' case, Mr. Lawrence remarked, that althongh the heart is most frequently displaced gradually, yet it may occur also suddenly. He had met with a case of this nature, in a boy 15 years of age, who was brought to St. Bartholomew's on account of having been severely crushed at the chest; on the day after admission, the heart was felt beating violently on the right side, and not distinguishable on the left side. The peculiarity was so very striking, and existing as it did without any very apparent cause, that $M \mathrm{Ir}$. Lawrence was at first disposed to attribute it to some connate malposition; however, in the course of treatment (antiphlogistic) the heart resumed its natural situation.

Mr. Trarers, in reply to Mr. Lawrence, said, that he gxounded his opinion of disease having existed in the chest for a longer period than three weeks, on the fact of the left lung being in a state of condensation, and yet so attenuated, that it might be said to form the parietes of the chest on the left side, being not more than two or three lines in thickness, and the pleura most intimately coherent. Such an appearance of the lung, he said, had been noticed by Haller, and was different from the dense condition of the lung described by Morgagni, Baillie, and others, and of common occurrence.

The other speakers were Dr. Birkbeck, Mr. Earle, and Dr. James Johnstone: Dr. Birkbeck alluded to the circumstance of Mr. 'Travers' patient having only com plained of trifling uneasiness about the chest, previously to the last illness, whereas close adhesion of the left pleural surfaces (the result of severe inflammation) had taken place. Mr. Earle briefly related a case of fungoid disease as an exemplification of the rapidity of its progress; Dr. Johnstone thought that auscultation, or even percussion, would have corrected the duagnosis in Mr. Travers' case.

\section{PHYSIOLOGY OF PARTURITION.}

\section{To the Editor of THE LANCET.}

Sir, - IN the report of a meeting of the London Medical Society, (17 Dec. 18,7)! published in The LANCET of the 22d Dec., a paper is noticed on the action of the respiratory muscles in parturition, in which Mir. Searle states that " the only writer who fully accords with the proposition, that the respiratory muscles are the principal agents in parturition, is Blumenbach." Had Mr. Searle made himself acquainted with the contents of the Translator's "Introduction to Mojon's Laws of Plyysiology," he would then have found that the translator had published numerous reasonings on the funtions of the uterus and respiratory mus. cles in the uterine phenomena.

Although little merit will be obtained for an attempt to remove the idea of the foetus being expelled by the spasmodic contractions of the uterus; I cannot allow that gentleman the claim of priority, even should that idea be supported by fact, as it is now by lurking prejudice.

Blumenbach considers the action of the respiratory muscles only among the remote causes of parturition, which is generally ad. mitted by obstetric artists; therefore I did not quote him as a particular authority; and a still further reason for not adducing this German philosopher as a support to my reasonings, is the fact of his asserring that, " the proximate and primary cause of parturition is solely the vita propria of the ute. rus." * 'This vita propria he calls a law of nature!

Thus it will be found that if merit is due to the promulgator of a new theory of parturition, and other functions of the uterus, namely, the menstrual discharge and the fotal venous circulation, \&c. it cannot be a tribute to be paid to the learned Blumen. bach.

Thanking you for the insertion of this letter in the popular pages of your Journal, I have the honour to be,
Sir,
Your obedient servant, George R. Skenf.

6, Jermyn Street, St. James's, 19th. Jan. 1828 .

* Dr. Elliotson's Translation of Blumen. bach's Institutes of Physiology, p. 303. sect. xli. 